example of this. The tubercles on the face of tubercular lepers frequently ulcerate, the vast quantities of the bacilli causing a local necrosis; cicatrisation occurs, and the tubercles diminish in consequence. C. A., a man, whose photograph is reproduced below, is such a case. He has had three attacks of erysipelas. The occurrence of these facts is so well known that I must claim pardon for introducing them, but this diminution in size of the tubercles is capable of misinterpretation and some fallacious cure of leprosy vaunted in consequence. I have never seen the least improvement occur in tubercular patients after erysipelas, but I have frequently seen the facial tubercles diminish during the course of phthisis or after superficial ulceration, and in the former case I have considered it to be due to the emaciated and anæmic condition of the patient.

Syphilis exists in the same individual side by side with leprosy, and the features of either disease do not appear to be materially changed. It is noteworthy that potassium iodide in particular exercises an injurious effect upon leprosy. It is unscientific to describe a syphilitic form of leprosy; one might as well describe a syphilitic measles.

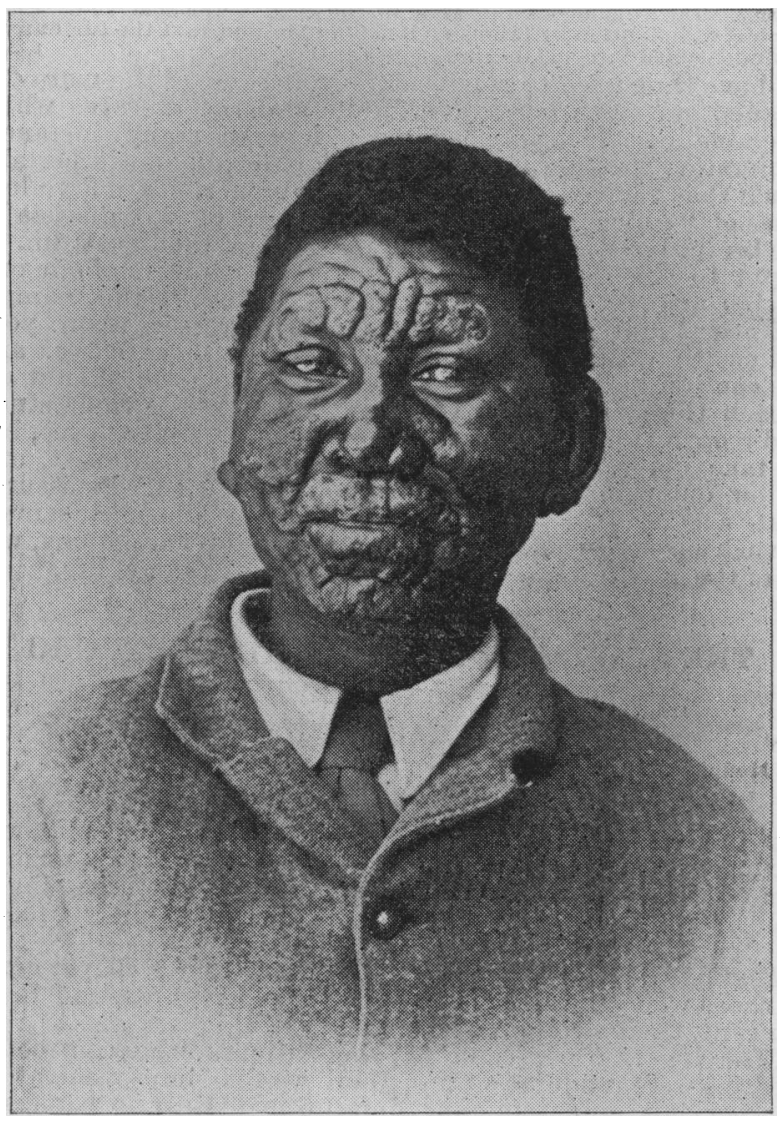

The onset of leprosy is most insidious and gradual. From this has originated the idea that the incubation period may be prolonged for varying periods, even to twenty years or more; such statements must be received with great caution. There can be no doubt that before objective symptoms appear the patient has been, possibly for a long period, a prey to neuralgic pains or other more obscure prodromata. It may, I believe, be accepted that the undermentioned patients were affected with leprosy some time before they contracted the other specific diseases, and if so it is evident these had no effect in modifying beneficially the course of leprosy. CASE I.-D.. a European affected with complete leprosy, was admitted
to Robben Island Leper Institution in November, r892. Towards the end of 1878 the patient contracted measles, an epidemic of which occurred where he was then living; one of his children died of the disease. The patient was in bed twenty-eight days, and during his recovery he noticed that he had lost feeling in his hands, the fingers of which became contracted during 1879 . Leprosy has progressed ever since.

CASE II.-L., a bastard, affected with complex leprosy, was admitted to Robben Island Leper Institution, April, 1892 . In $189 x$ the patient contracted measles during an epidemic. Three months after the measles he noticed a reddish.coloured patch, slightly raised above the level of the skin at the inner margin of his right eyebrow. The leprosy has progressed ever since.

CASE III.-F. P., a bastard, affected with tubercular leprosy, was admitted to Robben Island Leper Institution in March, 1893 . The patient contracted small-pex during the epidemic of 1882 ; he was living at Durbanville. near cape Town, and had a severe attack. Two months after recovery he noticed a yellow-coloured patch on the outer aspect of his right thigh; he had no feeling at this spot. Leprosy has progressed ever since, and on the patient's face, which is much tuberculated, can be seen the marks of pitting from small-pox.

\section{Analysis of TaBles.}

[Dr. Todd gives, in tabular form, particulars concerning 129 lepers who had had one or more attacks of erysipelas, 16 who had been attacked with measles, and 2 who had contracted syphilis since the onset of the leprosy.

The details tabulated consist of the index number, initials of name, sex, age, race, form of leprosy, date of admission tow Robben Island, date of onset of leprosy, date of known onset of intercurrent disease, number of attacks of latter, and lastly, condition of patient after intercurrent disease with regard to leprosy. The erysipelas cases comprise 1 cS males and 21 females; 30 of the whole number are of the asasthetic type of leprosy. The majority are comparatively recent cases, the date of onset of the leprosy being, in 60 of them, from 1890 , and only 26 date the commencement of the disease from 1885 or an earlier year. The intercurrent erysipelas, where noted. occurred either in the years 1893,1894 , or 1895. One patient has a record of to attacks of erysipelas in 1894,2 have had six attacks, 3 are credited with four, 8 with three, and 25 with two. Thirty-two of the erysipelas cases are at the present time dead, with the exception of the 7 who succumbed to erysipelas, the causes of death being such as are usual with leprous patients.

The result of Dr. Todd's observations is that, in spite of the statements made in Dr. Impey's recent work on leprosy, no real improvement is to be looked for in lepers by the contraction of erysipelas, measles, or syphilis; and he thus confirms the experience of others conversant with leprosy.]

\section{PUERPERAL FEVER TREATED BY ANTI- STREPTOCOCCUS SERUM.}

\section{BY HENRY L. G. LEASK, M.D., Glasgow.}

Mrs. G. A., aged 23, a primipara, was delivered of a large male child on March 19th, I896, at 5,45 A.M. Her labour was normal, the presentation cranial, L.o.A. throughout. More Madden's short straight forceps was applied to control and aid the passage of the head over the perineum, which escaped rupture. Soap and hot water, the use of the nailbrush, bichloride of mercury for the hands and creolin for the instruments and as a lubricant, comprise the antiseptic precautions taken. The after-treatment, however, was such as: is ordinarily carried out in the homes of the working class.

For some days all went well, and the morning and evening temperatures were normal. On visiting her on March 26th, I found her condition unsatisfactory, and was informed that she had not felt so well on the previous day, when she had shivered. Her condition resembled very bad influenza. There was no abdominal pain or tenderness, and no fœtor of the lochia from first to last.

That evening she had a douche of bichloride of mercury, in 1,000 , and this was repeated twice daily. Sulphate quinine gr.v in hydrobromic acid was given every four hours. The temperature, $103^{\circ}$ to $104.5^{\circ} \mathrm{F}$., did not yield to treatment.

On March 29th, I was compelled to stop the quinine on account of cinchonism. Biniodide of mercury gr. $\frac{1}{2}^{\frac{1}{2}}$ every four hours was substituted, and the intrauterine douching with this same antiseptic continued three times daily. The temperature was $105^{\circ}$, and the pulse $120^{\circ} \mathrm{F}$.

On March zoth Dr. W. L. Reid saw the patient at II A.M. 
and agreed as to the diagnosis. On examination the uterus and appendages were normal. There was a slight transverse laceration on the posterior vaginal wall one inch from the vulva-the probable site of infection. The temperature was $1^{\circ} 2^{\circ}$ F., and the pulse 98. From Mr. D. Watson, chemist, Govanhill, I had that morning procured a $20 \mathrm{c.cm}$. phial of antistreptococcus serum (Burroughs, Wellcome, and Co.) "guaranteed in good condition and free from microbes" by the signature "T. J. Bokenham," dated March 4th, 1896; and with Dr. Reid's approval, of this serum 4 c.cm. were injected in the evening at IO P.M., when the pulse was II4 and the temperature $104.5^{\circ} \mathrm{F}$

On the following morning (March 3 Ist) the temperature was $100^{\circ} \mathrm{F}$., the pulse 96 . The patient had slept soundly all night, and was very much brighter, feeling happier and stronger. None of the biniodide was given through the night. Tincture of nux vomica in $m 20$ doses three times a day was now ordered instead, as recommended by Dr. Reid. After this her pulse and temperature remained practically normal, and her recovery was uninterrupted.

The beneficial effect of the serum was very marked, the change for the better was so abrupt that it resembled very much the crisis of a lobar pneumonia. On the fifth day after the injection she sat up in an armchair for an hour to have her bed made, and by the tenth day ventured to go outside and take a walk. No bad symptom, locally or generally, followed the use of the serum; its influence was only for good.

\section{MEMORANDA: \\ MEDICAL, SURGICAL, OBSTETRICAL, THERA- PEUTICAL, PATHOLOGICAL, ETc.}

\section{EMBOLISM OF ABDOMINAL AORTA.}

ON February 28th, about 7 A.M., my assistant, Mr. Botham, found Mrs. S. with acute pain in the left chest, extending down the left arm. This attack continued about two hours. Mr. Botham considered it to be a severe attack of angina pectoris.

On February 29th I found Mrs. S. much relieved; she was dressed and downstairs. She still complained of slight pain over the lower part of the left side. I sent her an ordinary blister, and intended to see her again in a day or two. After this, her husband tells me, she seemed to get nearly all right again, but early on the morning of March 2nd, after Mr. S. had got up and gone down to breakfast, Mrs. S. suddenly lost all use in her legs, and was in great pain. Mr. Botham found her with no pulsation in the arteries of the lower extremities, which were slightly discoloured. $\mathrm{He}$ ordered them to be wrapped in cotton wool, and a flannel bandage to be put round the loins, and sent an opium pill to relieve her. I saw her the same night, and found she could not move her limbs, nor feel a scratching on the skin of the thighs or groins, or tickling of the feet. That night she passed a little water.

Next morning I saw her again and found her lower limbs discoloured and commencing to decompose. I passed a catheter. Dr. Frank Nicholson, of Hull, saw her that afternoon in consultation with me. He found a large heart but no valvular disease. He agreed with the diagnosis of embolism and gave a very unfavourable prognosis. The next day Mr. Botham saw her twice, and the last time on March 4th, about 10.30 P.M. She died on March 5th, about 4.30 A.M.

Previously to this attack Mrs. S. was in good health and presented no symptoms indicating heart disease. During the last two years she had complained occasionally of a little pain in the left side of the chest, but this she had put down to indigestion and did not think it necessary to call in medical assistance. Mrs. S. was quite conscious up to the last, and asked questions about what would happen to the limbs. There was a small quantity of albumen in the urine. During the whole time the pulse was very much accelerated. In all probability the common iliacs were plugged on the morning of March 2nd, yet the patient survived this accident for three days.

R. P. GoodworTH, L.R.C.P.ED,, M.R.C.S.Eng. Winterton, Doncaster.

A CASE OF LIPOMA OF THE PALM.

A MAN, aged 47, a year ago noticed a slight swelling of the ball of the left thumb. Within the last six months this had rapidly increased and become painful and tender, in consequence of which he had been unable to use his hand, his occupation being a gardener, as it was subjected to pressure in driving a spade into the ground.

The skin over the ball of the left thumb was much thickened from constant pressure. There was a solid elastic swelling of the ball of thumb, with some tenderness on pressure, and much limitation of movement due to tension.

Thinking it to be an adventitious bursa with thickened wall and fluid contents, it was punctured, but nothing escaped. An incision was made over the swelling. The abductor and opponens pollicis-so thinned as to be scarcely recognisable - separated, and in the intermuscular plane between these muscles and the flexor brevis pollicis a lipoma the size of a plover's egg shelled out with the handle of scalpel. The wound was closed and pressure applied. The tumour was found to be a pure lipoma by the Clinical Research Association: With active and passive movement and friction the hand grasp gradually returned.

REMARKs.- The patient, an intelligent man, is certain there was nothing noticeable until a year ago. The marked wasting, due I take it to pressure and disuse, and the unusual position for a lipoma.

Newton Abbot. Malcolm Margrave, M.R.C.S., L.R.C.P.

\section{CASE OF MELENA NEONATORUM PROBABLY} DUE TO CESOPHAGEAL ULCERATION.

As the true pathology of melæna neonatorum is still undetermined, and as the morbid anatomy has varied considerably in different published cases, it is, perhaps, well to put on record the following instance in which a definite lesion was discovered: The child was a female, born at full time in the Glasgow Maternity Hospital. Its weight was $5^{\frac{1}{2}}$ lbs. and its length $16 \frac{1}{2}$ inches. The mother's age was 19. When the infant was 1 day old it began to vomit dark brown blood, and on the following day it began to pass black blood by the bowel. These two symptoms continued and the child died when 3 days old. Professor Murdoch Cameron asked me to make a post-mortem examination.

The lungs were found to be very inelastic, with localised areas of congestion; the larynx, bronchi, heart, liver, and spleen were normal; the kidneys were lobulated; the urinary bladder was distended; the stomach and great part of the intestines were filled with thick dark red blood. The only lesion that could be discovered was a minute vertical linear erosion, with some congestion around it, in the lower part of the gullet on the right side, immediately before this part of the csophagus was continued into the lesser curvature of the stomach. In a microscopic section made through the seat of lesion this erosion was represented by a depression in one border of the section, and it was possible with the naked eye to recognise at one margin of the depression a slightly projecting point. The microscope showed this projecting tag to resemble a piece of blood vessel, which, in fact, it very probably was, and it is likely that it was the same blood vessel which was seen cut across in about half a dozen places underneath the surface. At the seat of erosion there was nothing suggestive of mucous membrane, but there was a well-marked infiltration of round cells which penetrated so deeply as to break up half the thickness of the more superficial muscular layer. It is exceedingly probable that the ulcerative process at this spot involved the blood vessel seen in the preparation, and so.brought about the fatal hæmorrhage. Unfortunately there is no suggestion to make as to the cause of the ulceration.

Glasgow.

T. K. Monro.

AT an examination for inspectors of nuisances held by the Sanitary Institute at Newcastle-on-Tyne on June 5 th and 6 th, twenty-four candidates presented themselves, to nine of whom certificates were granted. 